\title{
Randomised controlled non-inferiority trial of primary care based facilitated access to an alcohol reduction website (EFAR-FVG)
}

\author{
Paul Wallace ${ }^{1 *}$, Piero Struzzo ${ }^{2}$, Roberto della Vedova ${ }^{2}$, Costanza Tersar $^{2}$, Lisa Verbano ${ }^{2}$, Harris Lygidakis ${ }^{3}$, \\ Richard MacGregor ${ }^{4}$, Nick Freemantle ${ }^{5}$, Emanuele Scafato ${ }^{6}$ \\ From International Network on Brief Interventions for Alcohol and Other Drugs (INEBRIA) Meeting 2013 \\ Rome, Italy. 18-20 September 2013
}

\section{Introduction}

There is a strong body of evidence demonstrating effectiveness of brief interventions by primary care professionals for risky drinkers but implementation levels remain low. Facilitated access to an alcohol reduction website constitutes an innovative approach to brief intervention, offering a time-saving alternative to face to face intervention, but it is not known whether it is as effective.

\section{Objective}

To determine whether facilitated access to an alcohol reduction website is equivalent to face to face intervention.

\section{Methods}

Randomised controlled non-inferiority trial for risky drinkers comparing facilitated access to a dedicated website with face to face brief intervention conducted in primary care settings in the Region of Friuli Venezia-Giulia, Italy. Adult patients are given a leaflet inviting them to $\log$ on to a website to complete the AUDIT-C alcohol screening questionnaire. Screen positives are requested to complete an online trial module including consent, baseline assessment and randomisation to either standard intervention by the practitioner or facilitated access to an alcohol reduction website. Follow up assessment of risky drinking is undertaken online at 1 month, 3 months and 1 year using the full AUDIT questionnaire. Proportions of risky drinkers in each group will be calculated and non-inferiority assessed against a specified margin of $10 \%$. The trial is being undertaken as an initial pilot and a subsequent main trial.

\section{Results}

12 practices have participated in the pilot, and more than 1300 leaflets have been distributed. 89 patients have been recruited to the trial with a one month follow-up rate of $79 \%$.

\section{Discussion}

The findings of the pilot study suggest that the trial design is feasible, though modifications will be made to optimize performance in the main trial which will commence in January 2014. Plans are concurrently underway to replicate the trial in Australia, and potentially in the UK and Spain.

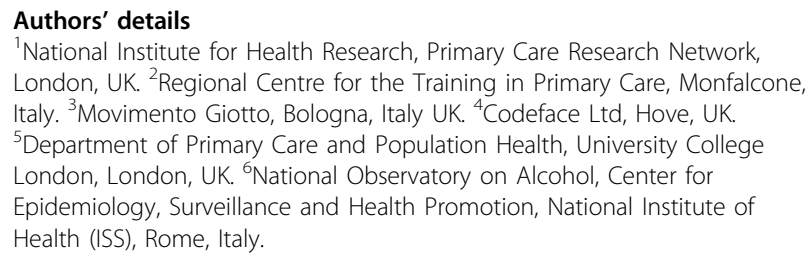

Published: 4 September 2013

\section{doi:10.1186/1940-0640-8-S1-A83}

Cite this article as: Wallace et al:: Randomised controlled non-inferiority trial of primary care based facilitated access to an alcohol reduction website (EFAR-FVG). Addiction Science \& Clinical Practice 2013 8(Suppl 1): A83.

\footnotetext{
* Correspondence: Paul.wallace@nihr.ac.uk

${ }^{1}$ National Institute for Health Research, Primary Care Research Network,

London, UK

Full list of author information is available at the end of the article
} 